\title{
The predictive capacity of perceived expressed emotion as a dynamic entity of adolescents from the general community
}

\author{
William W. Hale III • Quinten A. W. Raaijmakers • \\ Anne van Hoof • Wim H. J. Meeus
}

Received: 26 August 2009/ Accepted: 23 March 2010/Published online: 3 April 2010

(C) The Author(s) 2010. This article is published with open access at Springerlink.com

\begin{abstract}
Background In previous studies, it has been demonstrated that high parental expressed emotion (EE) is predictive of depressive, aggressive and delinquency symptoms of adolescents. Two issues have received much less prominence in EE research, these being studies of adolescent perceived $\mathrm{EE}$ and the measurement of the EE as a dynamic, developmental construct. This 4-year, three-wave, longitudinal study of perceived EE of adolescents from the general community examines if adolescent perceived EE measured with the traditional, one-measurement EE approach as well as adolescent perceived EE measured with a repeated measured, dynamic EE approach can predict adolescent depressive, aggressive and delinquency symptoms.

Methods Dutch adolescents $(N=285 ; 51 \%$ girls; $M=13$ years) from the general community were prospectively studied annually for 4 years. At all waves, the adolescents completed the Level of Expressed Emotion (LEE) questionnaire and at the final wave also completed self-rated measures of depressive, aggressive and delinquent symptoms. Growth models were used to predict adolescent symptoms from adolescent perceived EE.

Results Growth models significantly predicted adolescent depressive, aggressive and delinquency symptoms from adolescent perceived EE.

Conclusions This study of the LEE demonstrates that developmental characteristics of $\mathrm{EE}$ are predictive of
\end{abstract}

W. W. Hale III $(\bowtie) \cdot$ Q. A. W. Raaijmakers · W. H. J. Meeus Research Center Adolescent Development, Utrecht University, P.O. Box 80.140, 3508 TC Utrecht, The Netherlands e-mail: b.hale@uu.nl

A. van Hoof

Department of Development Psychology, Utrecht University, Utrecht, The Netherlands adolescents' symptoms. These findings hold implications for current EE intervention therapies and the conceptualization of EE.

Keywords Adolescent - Aggression - Depression · Development $\cdot$ Expressed emotion

\section{Introduction}

In previous studies, it has been demonstrated that high parental expressed emotion (EE) is predictive of psychopathological symptoms of children and adolescents. Three child and adolescent psychopathological symptoms categories that have received particular attention in EE studies are depressive, aggressive and delinquent psychopathological symptoms. In respect to depressive symptoms, it has been found that high parental EE is predictive of child and adolescent depressive symptoms [1-3]. High EE has also been predictive of child and adolescent aggressive and delinquent psychopathological symptoms [4-8].

It should be noted that the large majority of these EE studies have been conducted on populations in which either the child or parent has been diagnosed with a clinical mental disorder. Far less attention has been given to the study of EE and its relationship to depressive, aggressive and delinquent symptoms in adolescents from the general community. Clearly, research of clinical populations is naturally important for the validation of a scale purported to measure clinical symptomology. However, in respect to adolescents, several researchers have suggested that the referral bias with adolescent clinical populations may limit generalizability and argue that prospective, community studies of adolescents may better characterize the course of adolescent disorders $[9,10]$. 
Furthermore, two other issues have also received much less prominence in EE research, these being studies of adolescent perceived $\mathrm{EE}$ and the measurement of the $\mathrm{EE}$ as a dynamic, developmental construct. In respect to the former, all of the above-mentioned studies of EE and child and adolescent depressive, aggressive and delinquent psychopathological symptoms have been conducted with either the semi-structured Camberwell Family Interview (CFI) or the shortened Five Minute Speech Sample interview. In respect to EE interviews, Lobban et al. [11] have noted, "EE is a measure of the emotional climate within a relationship, although taken from the relatives' perspective." (p. 54). Therefore, a case can be made for studying the impact EE has on the recipient; in other words, the perceived EE. For example, while the few studies of the perception of EE of adult patients to their "significant other" (i.e., parent or partner) have found strong predictive relationships between perceived $\mathrm{EE}$ and adult psychopathology [12, 13], almost no attention has been given to child and adolescent perceived EE (a notable exception is the adolescent perceived EE study by Hale et al. [14]). This lack of study of adolescent perceived EE is curious since cognitive theories underlying EE research assume that both the parents' giving of EE as well as the adolescent's receiving of EE affects the individual's psychopathological symptoms. Hence, how EE is perceived would seemingly be just as an important component to the prediction of individual's psychopathological symptoms as the actual given EE.

The second outstanding issue, the measurement of the EE as a dynamic, developmental construct, has received little consideration. In many other fields of study of the effects of parental behaviors and attitudes on child and adolescent psychopathological symptoms, the measurement of parental behaviors and attitudes is conducted on several occasions to examine how dynamic changes in parental behaviors and attitudes predict child and adolescent psychopathological symptoms. Traditionally, CFI studies have measured EE at Time 1 and have predicted child and adolescent psychopathological symptoms at Time 2. It is quite conceivable that since CFI does not easily lend itself to repeated measurement that the CFI has been treated as a static entity, unchanging over time. Hence, while the CFI has predicted child and adolescent psychopathological symptoms, it has not been able to analyze the possible effects of the dynamics in these parental behaviors and attitudes.

Hence, in this three-wave longitudinal study of adolescent perceived EE, we will examine perceived EE of adolescents from the general community with both the traditional one-measurement EE approach as well as adolescent perceived EE with a repeated measured, dynamic $\mathrm{EE}$ approach to predict child and adolescent depressive, aggressive and delinquent psychopathological symptoms. Since a longitudinal study of adolescent perceived EE as a predictor of child and adolescent depressive, aggressive and delinquent psychopathological symptoms has not been previously conducted in adolescents from the general community, no specific hypotheses were formulated, and therefore, the data were analyzed in an exploratory manner. However, it would seem to be the case that the knowledge yielded from both approaches, conducted in one-andthe-same design, will help further our knowledge of the predictive capacity of the EE construct, a primary aim of EE research [15].

\section{Methods}

\section{Subjects}

In 2002, 308 Dutch secondary school adolescent respondents participated in the first wave of this three-wave study. The data for the second and third waves were collected 2 and 3 years after the first wave, in 2004 and 2005. These students came from various Dutch (junior) high schools in the Utrecht province of The Netherlands. The participating adolescents in this study of EE are a randomly selected sub-sample of a larger, ongoing research study of Dutch adolescent students and their families. Of the initial 308 students, 23 (7\%) students turned in completely blank questionnaires of one or more of the research variables at one or more researched waves, hence they were excluded from further analyses. The excluded 23 students did not significantly differ from the researched group (285 students) in terms of age, gender or family composition. In waves 1, 2, and 3, the number of participants was 308, 297, and 285 , respectively.

The adolescent population was comprised of 139 (49\%) boys and $146(51 \%)$ girls. The age of the students at the first moment of measurement ranged from 12 to 15 $(M=13.3 ; \mathrm{SD}=0.51)$; the large majority were 13 years of age (67\%). Of the 285 students, 279 (98\%) came from two parent families.

\section{Procedure}

The adolescents that participated in this study filled in the EE questionnaire for the first and second waves of the study and the EE, Depression, Aggression and Delinquency questionnaires in the third wave of the study, at home, under the supervision of a research assistant. Before the study, both adolescents and their parents received written information. If the adolescent elected to participate, the parents were then required to provide written informed 
consent; less than $1 \%$ elected not to participate. The research assistant then called the home phone number of the adolescent (which was requested on the consent form) and made an appointment with the adolescent when the assistant could come to their home to present the questionnaires. Verbal instructions were given just prior to the testing to compliment the written instructions printed above each questionnaire. Other research assistants conducted the data entry to ensure that the data remained anonymous.

\section{Measures}

\section{Adolescent perceived expressed emotion}

This study employed the 38-item revised version of the Level of Expressed Emotion (LEE) questionnaire, which takes approximately $5 \mathrm{~min}$ to complete. In a factor analytic study by Gerlsma et al. [16], the original 60 -item LEE questionnaire [17], designed for adult subjects, was reduced to a 33-item questionnaire with three scales: perceived lack of emotional support (19-items), perceived intrusiveness (7-items) and perceived irritation (7-items). Each item is scored on a scale from 1 to 4 (1 untrue; 2 somewhat untrue; 3 somewhat true; 4 true). The factor structure of this 33-item revised LEE was confirmed in an independent confirmatory factor analysis by Startup [18]. In a study by Gerlsma and Hale [12], a fourth scale was added: perceived criticism (5-items). The perceived criticism scale and the newly revised 38-item LEE were shown to have good psychometric properties [12].

In a recent study by Hale et al. [14], confirmatory factor analyses demonstrated that the four factor structure of the 38-item revised version of the LEE applied to adolescents in the same way it has previously been shown to apply to adults $[12,16,18]$. Additionally, the internal consistencies of the scales were good and all the inter-correlations between the scales were significant. Furthermore, the factors were significantly correlated to adolescent depressive and anxiety symptom score dimensions.

In addition to these four scales, a new (fifth) scale was also included in this study, entitled perceived constructive criticism (8-items). While the CFI measures the number of positive comments the family member expresses about the patient, little is known about the influence of the number of positive comments dimension and this measure has been largely ignored [19]. This scale, written by the first author, was constructed to reflect the EE-positive comments scale (and, to a lesser extent, the EE warmth scale) as well as to fit within the questions posed by the revised 38 -item version of the LEE. The questions of these eight items are "My parents teach me new things with their critical remarks"; "My parents give me helpful suggestions"; "My parents give me criticism without attacking me"; "My parents tell me what they think of me in a respectful manner"; "My parents' criticism of me is constructive"; "My parents let me know they are interested in me with their remarks"; "My parents give me criticism that I find valuable"; "My parents build my self-confidence with their remarks".

This modified version of the LEE (both the items and the scale-scoring key) is available by request from the first author.

In this study, Cronbach's alphas for the LEE were perceived lack of emotional support $0.88 / 0.93 / 0.89$, perceived intrusiveness $0.83 / 0.86 / 0.87$, perceived irritation $0.81 / 0.84$ / 0.84 , perceived criticism $0.71 / 0.75 / 0.79$, perceived constructive criticism $0.80 / 0.87 / 0.90$ for each of the three waves, respectively.

\section{Adolescent depression symptoms}

The Children's Depression Inventory (CDI) is a widely utilized self-report questionnaire of depressive symptomology in children and adolescents for ages of 8-18 years [20]. The questionnaire is composed of 27 items that review the various depressive symptoms categories such as mood, vegetative, cognitive and psychomotor disturbances. The questionnaire is scored on a three-point scale ranging from "not true", "a bit true" to "very true". Two sample questions are "I am sad the entire day" and "Nothing is fun anymore". The CDI has strong internal consistency and validity in non-clinical populations [21]. In this study, Cronbach alpha for the CDI was 0.85 .

\section{Adolescent aggression behaviors}

The adolescents' aggression was measured by the DirectIndirect Aggression Scale (DIAS) [22]. The direct aggression scale of the DIAS was used in this study. The questionnaire asks what the adolescent would do to a classmate when the adolescent was angry with the classmate. This is a measurement of how adolescents react to classmates when angry; hence, it is a situational measurement. However, it has been found that child and adolescent self-ratings of situational aggression is significantly correlated with that of similar peer-rated reports, leading to the idea that self-ratings of aggression can be used to measure general child and adolescent aggression [23].

Reliability and construct validity have been shown to be strong $[24,25]$. The questions were scored on a scale from 1 ("never") to 4 ("always"). Two sample questions are "If I am mad or upset with someone in my class..." "...I will call him (or her) names" and "...I will kick or hit him (or her)". Cronbach's alpha for the direct aggression scale of the DIAS was 0.81 . 


\section{Adolescent delinquency behaviors}

The Adolescent Delinquency Behaviors questionnaire is a self-report questionnaire, which measures the frequency of several minor offences [26]. The use of self-report data is widespread in criminology, and it is a valid instrument when restricted to petty crime [27]. Adolescents were asked how many times they had committed 16 minor offences, such as being caught by the police for doing something, stealing a bike and deliberately damaging or breaking something in the street, in the past 12 months. The items were scored on a 4-point scale, ranging from 'never', 'once', 'two to three times' to 'four times or more'. Cronbach's alpha for the Adolescent Delinquency Behaviors questionnaire was 0.84 .

\section{Strategy of analysis}

The strategy of analysis consisted of three different steps of structural equation modeling (Amos version 7.0 [28]). The first, preliminary step was aimed at arriving at a fitting model describing the development of scores on the five subscales of the LEE, separately. Based on the results of this first step, the second step was made up of building a model in which parameters characterizing the development of LEE scores were represented as predictive of future problem behavior symptoms. In the third step, possible gender differences in the development of LEE scores and its relationships with problem behavior symptoms were further explored and tested.

\section{Preliminary analyses: modeling growth of LEE scores}

In this study, only three repeated measurement occasions were collected, which is insufficient for testing non-linear growth. In quadratic growth models, in addition to the intercept and slope, a third term, curvation, is included and several authors have pointed out that four or more measurement occasions are required to test quadratic growth models [29, 30]. Therefore, two kinds of linear models were tested (1) a monotone linear growth model, in which development is modeled as a straight line from moment 1 through moment 2 to moment 3; such a model is obtained by defining the factor loadings of the latent slope factor as linearly parameterized at the values of 0,1 en 1.5 (corresponding with the time lags between occasion 1 and 2, and occasion 2 and 3), and (2) a non-monotone linear or unspecified growth model, in which development is modeled as two consecutive straight lines with different angles (i.e., one line from moment 1 to moment 2, and one line from moment 2 to moment 3 ); such a model is obtained by freely estimating the third factor loading of the slope factor. This represents the only possible approach of modeling non-linear growth when just three moments of measurements are available [31]. In both these models, the residual error variances were constrained to be equal for similar LEE scores at different occasions.

Although the monotone linear model sufficiently fitted the development in scores on the LEE subscales Irritability, Criticism and Constructive Criticism, the non-monotone model had an equally good fit. Additionally, the nonmonotone model demonstrated a significantly better fit for the development in scores on the remaining LEE subscales emotional support and intrusiveness. For reasons of clarity, identical models were finally used for describing the development of scores on the different subscales of the LEE. Therefore, the third factor loading of the slope factor was freely estimated in all of the models.

\section{Prediction of problem behavior symptoms by the non-monotone linear model of the LEE scales}

Figure 1 depicts the non-monotone linear model that was employed to analyze the effects of the growth characteristics of the LEE scores on future problem behavior symptoms. The upper part of this model represents the development of the three scale score measurements of a LEE scale, resulting in the latent growth parameters of intercept and slope. The lower part depicts the effects the intercept and slope growth characteristics have on the adolescents' problem behavior symptoms (i.e., depression, direct aggression and delinquency at time 3). In this model, the residual error variances (E1-E3) are constrained to be equal across occasions, the third slope factor loading (SL3) is freely estimated, the intercept and slope-as exogenous variables - are assumed to be correlated (Intercept $\leftrightarrow$ Slope), just as the residual variances of adjacent problem behavior symptoms (Depression $\leftrightarrow$ Direct Aggression and Direct Aggression $\leftrightarrow$ Delinquency).

\section{Results}

Model fit

In Table 1, the ranges, means and standard deviations of the research variables are presented. On the basis of these results, the model as depicted in Fig. 1 was tested.

Table 2 reports the fit statistics of this model, specified for each of the four LEE scales (Perceived Lack of Emotional Support, Perceived Intrusiveness, Perceived Irritation and Perceived Criticism) as well as the new LEE scale (Perceived Constructive Criticism). Several fit indexes are reported. A non-significant $\chi^{2}$ value implies that the model does not significantly deviate from the observed data. As this measure is highly sensitive to 


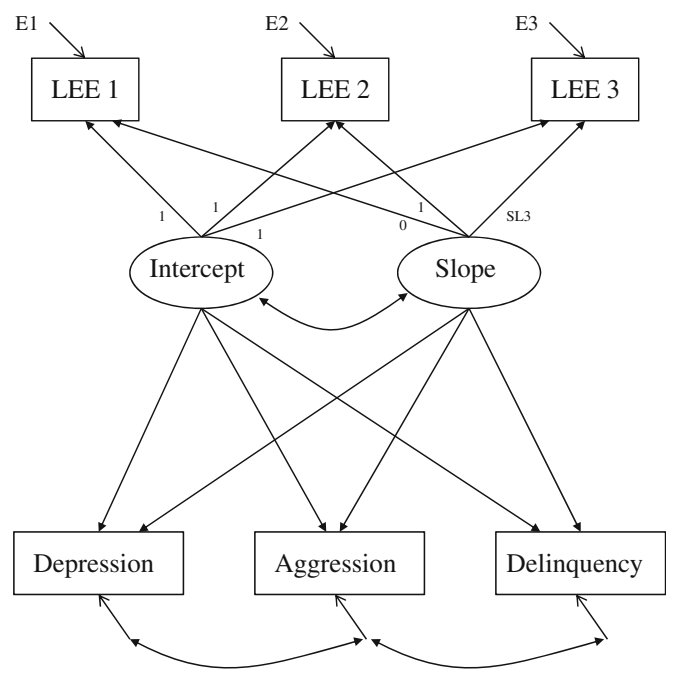

Fig. 1 Non-monotone linear growth model of repeated LEE scores predicting adolescent depressive, aggressive and delinquency symptoms. SL3 freely estimated factor loading

sample size, additional fit indexes are reported. The Comparative Fit Index (CF Index) indicates the proportion in the improvement of the model fit compared to the fit of a model assuming independence between the model variables. Values of 0.95 and higher reflect a good fit. The root mean square error of approximation (RMSEA) reflects the degree to which the model is considered to be incorrect in the population. The index is sensitive to model complexity in that it favors the more parsimonious models. Values $<0.05$ are indicative of a good fit, and values $<0.08$ (or 0.10 ) are accepted as reasonable (if accompanied by reasonable confidence intervals). The standardized root meansquared residual (SRMR) equals the standardized average covariance residual (i.e., the difference between model implied and observed covariances); values $<0.05$ are assumed to be indicative of a good fit.
Table 2 Latent growth model of the LEE scales, with growth parameters predicting levels of adolescent depressive, aggressive and delinquency symptoms: summary of fit statistics

\begin{tabular}{lrllllll}
\hline $\begin{array}{l}\text { LEE } \\
\text { scale }\end{array}$ & $\chi^{2}$ & $d f$ & $p$ & $\begin{array}{l}\text { CF } \\
\text { index }\end{array}$ & RMSEA & $\begin{array}{l}\text { 90\% CI of } \\
\text { RMSEA }\end{array}$ & SRMR \\
\hline ES & 28.031 & 6 & 0.000 & 0.950 & 0.114 & $0.073-0.158$ & 0.0436 \\
IN & 9.656 & 6 & 0.140 & 0.989 & 0.046 & $0.000-0.098$ & 0.0261 \\
IR & 12.288 & 6 & 0.056 & 0.981 & 0.061 & $0.000-0.109$ & 0.0382 \\
CR & 16.086 & 6 & 0.013 & 0.972 & 0.077 & $0.032-0.124$ & 0.0405 \\
CC & 7.331 & 6 & 0.291 & 0.994 & 0.028 & $0.000-0.086$ & 0.0257 \\
\hline
\end{tabular}

$E S$ perceived lack of emotional support, $I N$ perceived intrusiveness, $I R$ perceived irritability, $C R$ perceived criticism, $C C$ perceived constructive criticism

Examining the values of the fit indexes reported in Table 2 reveals that the models generally showed a good fit except for the lack of emotional support scale, for which the findings are less clear-cut. However, when the CF Index and SRMR values are taken into consideration, the fit of this LEE scale model also seems acceptable.

Growth parameters of LEE scores

Mean intercept and slope values of the different LEE sub-scales are reported in Table 3. Due to the parameterization of the slope factor loadings in the non-monotone growth model (Fig. 1), the mean intercepts reflect the mean scores at time 1 . The slope values are indicative of the direction and significance of the mean development from thereon.

It would appear from the results that the scores for Intrusiveness and Criticism remained relatively stable across measurement occasions (i.e., the mean slope values are not significantly deviant from zero). Mean scores for lack of emotional support, irritability and constructive

Table 1 Descriptive statistics of the research variables

\begin{tabular}{|c|c|c|c|c|c|c|c|c|c|}
\hline \multirow[t]{2}{*}{ LEE scales } & \multicolumn{3}{|c|}{ Wave 1} & \multicolumn{3}{|c|}{ Wave 2} & \multicolumn{3}{|c|}{ Wave 3} \\
\hline & Range & $M^{\mathrm{a}}$ & SD & Range & $M^{\mathrm{a}}$ & $\mathrm{SD}$ & Range & $M^{\mathrm{a}}$ & SD \\
\hline ES & 1.89 & 1.46 & 0.36 & 2.88 & 1.54 & 0.45 & 3.00 & 1.50 & 0.40 \\
\hline IN & 3.00 & 2.21 & 0.59 & 3.04 & 2.10 & 0.63 & 3.00 & 2.16 & 0.67 \\
\hline IR & 2.38 & 1.61 & 0.52 & 2.57 & 1.73 & 0.54 & 2.59 & 1.80 & 0.59 \\
\hline $\mathrm{CR}$ & 2.60 & 1.58 & 0.48 & 2.80 & 1.59 & 0.50 & 2.20 & 1.63 & 0.53 \\
\hline $\mathrm{CC}$ & 2.86 & 3.20 & 0.49 & 2.42 & 3.32 & 0.52 & 2.32 & 3.37 & 0.54 \\
\hline Depression & & & & & & & 1.04 & 1.16 & 0.18 \\
\hline Aggression & & & & & & & 1.75 & 1.42 & 0.44 \\
\hline Delinquency & & & & & & & 2.00 & 1.13 & 0.27 \\
\hline
\end{tabular}

$E S$ perceived lack of emotional support, $I N$ perceived intrusiveness, $I R$ perceived irritability, $C R$ perceived criticism, $C C$ perceived constructive criticism

a Each individual's score on a subscale of the LEE is computed as the mean of the response values of the items of that subscale 
Table 3 Intercept and slope values of LEE scale scores

\begin{tabular}{|c|c|c|c|c|c|c|}
\hline \multirow[t]{2}{*}{ LEE scale } & \multicolumn{3}{|c|}{ Intercept } & \multicolumn{3}{|l|}{ Slope } \\
\hline & $M$ & $(\mathrm{SE}$ of $M)$ & $p$ & $M$ & $(\mathrm{SE}$ of $M)$ & $p$ \\
\hline Perceived lack of emotional support & 1.457 & $(0.021)$ & $* * *$ & 0.066 & $(0.023)$ & 0.005 \\
\hline Perceived intrusiveness & 2.204 & $(0.035)$ & $* * *$ & -0.065 & $(0.035)$ & 0.061 \\
\hline Perceived irritability & 1.607 & $(0.029)$ & $* * *$ & 0.137 & $(0.028)$ & $* * *$ \\
\hline Perceived criticism & 1.570 & $(0.028)$ & $* * *$ & 0.035 & $(0.022)$ & 0.107 \\
\hline Perceived constructive criticism & 3.196 & $(0.029)$ & $* * *$ & 0.129 & $(0.030)$ & $* * *$ \\
\hline
\end{tabular}

$* * * p<0.001$

Table 4 LEE intercept and slope values as predictors of adolescent depressive, aggressive and delinquency scores

\begin{tabular}{|c|c|c|c|c|c|c|c|c|}
\hline \multirow[t]{2}{*}{ LEE scale } & \multicolumn{3}{|c|}{ Effect of intercept } & \multicolumn{5}{|l|}{ Effects of slope $B$} \\
\hline & $B(\mathrm{SE}$ of $B)$ & $\beta$ & $(p)$ & $B(\mathrm{SE}$ of $B)$ & $\beta$ & $(p)$ & $M R^{2}$ & $(p)$ \\
\hline \multicolumn{9}{|c|}{ Perceived lack of emotional support } \\
\hline Depression & $0.082(0.050)$ & 0.126 & $(0.101)$ & $0.242(0.064)$ & 0.357 & $(* * *)$ & 0.143 & $(0.012)$ \\
\hline Aggression & $0.491(0.119)$ & 0.309 & $(* * *)$ & $0.133(0.144)$ & 0.080 & $(0.356)$ & 0.102 & $(0.011)$ \\
\hline Delinquency & $0.290(0.071)$ & 0.296 & $(* * *)$ & $0.130(0.085)$ & 0.128 & $(0.125)$ & 0.104 & $(0.007)$ \\
\hline \multicolumn{9}{|c|}{ Perceived intrusiveness } \\
\hline Depression & $0.069(0.026)$ & 0.186 & $(0.008)$ & $0.055(0.031)$ & 0.137 & $(0.076)$ & 0.036 & $(0.125)$ \\
\hline Aggression & $0.096(0.065)$ & 0.105 & $(0.143)$ & $-0.040(0.077)$ & -0.041 & $(0.603)$ & 0.016 & $(0.414)$ \\
\hline Delinquency & $0.088(0.040)$ & 0.157 & $(0.027)$ & $0.064(0.047)$ & 0.105 & $(0.177)$ & 0.024 & $(0.214)$ \\
\hline \multicolumn{9}{|c|}{ Perceived irritability } \\
\hline Depression & $0.109(0.033)$ & 0.231 & $(0.001)$ & $0.174(0.049)$ & 0.299 & $(* * *)$ & 0.112 & $(0.008)$ \\
\hline Aggression & $0.354(0.083)$ & 0.256 & $(* * *)$ & $0.153(0.116)$ & 0.108 & $(0.186)$ & 0.092 & $(0.017)$ \\
\hline Delinquency & $0.209(0.051)$ & 0.296 & $(* * *)$ & $0.121(0.070)$ & 0.138 & $(0.086)$ & 0.088 & $(0.017)$ \\
\hline \multicolumn{9}{|c|}{ Perceived criticism } \\
\hline Depression & $0.108(0.033)$ & 0.224 & $(0.001)$ & $0.153(0.088)$ & 0.175 & $(0.084)$ & 0.068 & $(0.045)$ \\
\hline Aggression & $0.437(0.085)$ & 0.371 & $(* * *)$ & $-0.008(0.221)$ & -0.004 & $(0.970)$ & 0.138 & (0.007) \\
\hline Delinquency & $0.224(0.049)$ & 0.310 & $(* * *)$ & $0.211(0.128)$ & 0.160 & (0.099) & 0.105 & $(0.006)$ \\
\hline \multicolumn{9}{|c|}{ Perceived constructive criticism } \\
\hline Depression & $-0.069(0.051)$ & -0.124 & $(0.178)$ & $-0.358(0.102)$ & -0.510 & $(* * *)$ & 0.250 & (0.019) \\
\hline Aggression & $-0.442(0.130)$ & -0.323 & $(* * *)$ & $0.174(0.205)$ & 0.101 & (0.395) & 0.128 & $(0.083)$ \\
\hline Delinquency & $-0.234(0.071)$ & -0.279 & $(0.001)$ & $0.035(0.100)$ & 0.033 & $(0.724)$ & 0.083 & $(0.118)$ \\
\hline
\end{tabular}

$* * * p<0.001$

criticism showed a significant increase over the years, adolescents perceived their parents as becoming less emotionally supportive, more irritable and, conversely, providing more positive criticism.

Effects of the growth characteristics of the LEE

Table 4 reports for each scale of the LEE the regression coefficients associated with the effects intercept and slope values of the repeated LEE scores have on the levels of the scores measuring the adolescents' depression, direct aggression, and delinquency symptoms. Squared multiple correlations also are reported as an indication of the size of these effects.

As expected, and irrespective of the specific scale, the intercept of the LEE scores predicted most all of the problem behavior symptoms. Perceived lack of emotional support, intrusiveness, irritability, and criticism positively predicted the prevalence of these behaviors. Perceived constructive criticism had the opposite effect. These effects were rather consistent, with only a few exceptions delivering non-significant but similar effects (i.e., lack of emotional support and depression, intrusiveness and direct aggression, and constructive criticism and depression). 
Additionally, the slopes of the repeated LEE scores that significantly deviated from zero consistently and strongly affected the adolescents' depressive symptoms, but no effects could be observed concerning the remaining child problems. An increase in irritability and lack of emotional support, just as a decrease in constructive criticism positively affected the adolescents' level of depressive behavior symptoms.

\section{Sex differences}

In a multiple group analysis, possible differences between boys and girls in parameter estimates (i.e., intercepts, slopes, regression weights, covariances and estimated means) were analyzed. As expected, the outcome variables all revealed significant differences in mean levels $(p s<0.001)$. These differences varied from moderate (depression and delinquency) to large (direct aggression) with boys showing less depressive, more aggressive, and more delinquent behavior symptoms. Concerning the remaining model parameters, no sex differences could be observed, except for the estimated correlations between the residuals of the outcome variables. For boys, moderate correlations between the residuals of depressive and aggressive behavior symptoms were obtained, whereas these correlations were absent in girls. Moreover, the correlations between the residuals of direct aggression and delinquency were significantly stronger for boys than for girls (for boys, the values of correlation coefficients ranged from 0.31 to 0.35 , and for girls from 0.14 to 0.23 ).

\section{Discussion}

In the study, it was demonstrated that the intercept scores of all four of the previously established LEE scales (Perceived Lack of Emotional Support, Intrusiveness, Irritability, and Criticism) as well as the new LEE scale (Perceived Constructive Criticism) predicted depressive, aggressive and delinquency behavior symptoms of adolescents from the general community. Furthermore, all the slope scores of the LEE scales that were significantly different from zero (i.e., which indicate growth; see Table 3) only affected adolescent depression symptoms (Table 4). Finally, these effects did not differ between the adolescent boys and girls.

If the adolescent aggression and delinquency symptoms are operationalized as being primarily behavioral in nature and adolescent depressive symptoms as being primarily cognitive in nature, an interesting pattern occurs. When perceived $\mathrm{EE}$ is used as a one-time measure to predict adolescent problem behavior symptoms, it generally predicts both adolescent behavioral and cognitive problem behavior symptoms. In other words, adolescent behavioral and cognitive problem behavior symptoms seem to be reactions against a perceived high EE home environment. However, when perceived EE is operationalized as a developmental dynamic entity, it affects only adolescent cognitive problem behavior symptoms. It would, therefore, appear that the development of perceived EE affects the adolescent's thinking patterns, at least in respect to adolescent cognitive problem behavior symptoms. Taken together, not only does a one-time measure of perceived EE predict adolescent reactions (as has been found in previous studies), but the measurement of perceived EE as a dynamic entity demonstrates that it also affects adolescent thinking patterns. The latter finding is in agreement with previous research in which the development of depression cognitions have been shown to be particularly sensitive to the development of negative interpersonal interactions that act to reinforce these depression cognitions [32].

Knowledge that EE is also a dynamic, developing entity that predicts adolescent depressive symptoms, may lead to future insights into EE clinical interventions. For example, it has been noted that $\mathrm{EE}$ research has been a strong impetus in the creation of both family therapies and hospital-staff interventions that focus on the role EE plays in interacting with persons with psychopathological problems [33, 34]. While some studies have demonstrated that high EE is related to the negative illness perceptions of caretakers toward their patients [11], not all studies have been able to replicate these findings [35]. Therefore, EE measurements that allow for repeated measures of EE development, such as the LEE's measurement of perceived EE, might be an important addition to the instrument arsenal available to researchers of EE caretaker-patient relationships.

Furthermore, in a related note, it has been argued [36] that EE be included in the upcoming fifth revision of the Diagnostic and Statistical Manual of the Mental Disorder (DSM-V) since the EE construct might help to consolidate the Relational Problems sections of the present DSM-IV-TR [37]. It is suggested that clarity and codification of the DSM's Relational Problems section by means of EE might be of help to clinicians that employ family based interventions that focus on EE reduction [36]. If the predictive properties of $\mathrm{EE}$ are comprised of both a one-measure component and a dynamic, developmental component, then this not only will have importance on the theoretic underpinnings of psychotherapeutic interventions, but also on the conceptualization of the nature of psychopathological interactions as well.

In respect to the limitations of this study, it should be noted that the LEE was measured without a comparison to CFI measurements of EE. This limitation of questionnairebased measures of $\mathrm{EE}$ has been raised in several recent 
articles on the subject, while also raising the need for clinically useful and accessible CFI alternatives [15, 36]. Therefore, it is not possible to judge if the LEE findings of this study would be comparable to CFI measured EE. However, since LEE is a measure of perceived EE, there might be a difference between the provider's EE (as measured by the CFI) and the recipient's perceived EE (as measured by the LEE). Hence, in future studies it may be advisable to also measure the provider's perception of their EE with a modified version of the LEE questions to enable a direct comparison of LEE and CFI scores.

A second limitation of this study is that only the perceived EE of the adolescent was studied while the (provided) $\mathrm{EE}$ of the parents were not measured, as has been done in most previous studies of EE. However, a compelling reason to study adolescents' perceived EE is the suggestion that the subjective experience of being "brought up" more strongly influences adolescent development [38] and more strongly relates to adolescent adjustment and mental health than parents' reports of their upbringing behaviors [39]. While parental reports were not collected in this study, it is clear that the adolescents' perception of parental EE was clearly predictive of adolescent depressive, aggressive and delinquent psychopathological symptoms when measured in a traditional onemeasurement EE approach (as demonstrated by the intercept findings of the LEE scales). These findings agree with the results of previous child and adolescent EE studies and are suggestive of the utility of the LEE as an alternative measure of EE, specifically the LEE being a measure of perceived EE.

Our design focused on the relationships of both initial level and developmental changes of EE ratings with future child problem behavior symptoms. Another limitation of this study concerns the lack of repeated measurement of these problem behavior symptoms. The possible effects that child problems in turn might have on EE ratings are, therefore, ignored. At the same time, the lack of data regarding the level of problem behaviors at $\mathrm{T} 1$ and/or T2 makes it impossible to control for other factors affecting the baseline levels of these symptoms.

Despite of these limitations, the results of this study at least demonstrate that levels of child problems are not only consistently and significantly associated with initial levels of EE ratings, but also with specific characteristics of the development in EE ratings. This relationship of changes in the level of EE ratings with child problem behaviors is as consistent and significant as the relationship of initial levels of EE, though limited to the specific domain of depressive symptoms.

Finally, it should also be noted that while depressive, aggressive and delinquency problem behavior symptoms of adolescents from the general community were measured by questionnaires, it should be stated that such measures are not equivalent to the diagnosis of psychiatric disorders. Furthermore, this study only examined adolescents from the general population. Therefore, while these findings may reflect how adolescent perceived EE is related to emotional states, future study of perceived EE is needed to relate this to actual psychiatric disorders. However, in respect to adolescents, several researchers have suggested that the referral bias with adolescent clinical populations may limit generalizability and these researchers argue that prospective, community studies of adolescents may better characterize the course of adolescent disorders $[9,10]$.

Acknowledgments This study was fully funded by the Research Center Adolescent Development at Utrecht University. None of the authors have financial ties with for-profit enterprises and have no competing interests.

Open Access This article is distributed under the terms of the Creative Commons Attribution Noncommercial License which permits any noncommercial use, distribution, and reproduction in any medium, provided the original author(s) and source are credited.

\section{References}

1. Asarnow JR, Goldstein MJ, Tompson M, Guthrie D (1993) Oneyear outcomes of depressive disorders in child psychiatric in-patients: evaluation of the prognostic power of a brief measure of expressed emotion. J Child Psychol Psychiatry 34:129-137

2. Asarnow JR, Tompson M, Hamilton EB, Goldstein MJ, Guthrie D (1994) Family expressed emotion, childhood-onset depression, and childhood-onset schizophrenia spectrum disorders: is expressed emotion a nonspecific correlate of child psychopathology or a specific risk factor for depression? J Abnorm Child Psychol 22:129-146

3. Hirshfeld DR, Biederman J, Brody L, Faraone SV, Rosenbaum JF (1997) Associations between expressed emotion and child behavioral inhibition and psychopathology: a pilot study. J Am Acad Child Adolesc Psychiatry 36:205-213

4. Peris TS, Baker B (2000) Applications of the expressed emotion construct to young children with externalizing behavior: stability and prediction over time. J Child Psychol Psychiatry 41:457-482

5. Peris TS, Hinshaw SP (2003) Family dynamics and preadolescent girls with ADHD: the relationship between expressed emotion, ADHD symptomatology, and comorbid disruptive behavior. J Child Psychol Psychiatry 44:1177-1190

6. Psychogiou L, Daley DM, Thompson MJ, Sonuga-Barke EJS (2007) Mothers' expressed emotion toward their school-aged sons. Associations with child and maternal symptoms of psychopathology. Eur Child Adolesc Psychiatry 16:458-464

7. Stubbe D, Zahner G, Goldstein M, Leckman J (1993) Diagnostic specificity of a brief measure of expressed emotion: a community study of children. J Child Psychol Psychiatry 34:139-154

8. Vostanis P, Nicholls J, Harrington R (1994) Maternal expressed emotion in conduct and emotional disorders of childhood. J Child Psychol Psychiatry 35:365-376

9. Pine DS, Cohen P, Gurley D, Brook J, Ma Y (1998) The risk for early-adulthood anxiety and depressive disorders in adolescents with anxiety and depressive disorders. Arch Gen Psychiatry 55:56-64 
10. Woodruff-Borden J, Leyfer OT (2006) Anxiety and fear. In: Hersen M (ed) Clinician's handbook of child behavioral assessment. Elsevier Academic Press, San Diego, pp 267289

11. Lobban F, Barrowclough C, Jones S (2006) Does expressed emotion need to be understood within a more systemic framework? An examination of discrepancies in appraisals between patients diagnosed with schizophrenia and their relatives. Soc Psychiatry Psychiatr Epidemiol 41:50-55

12. Gerlsma C, Hale WW III (1997) Predictive power and construct validity of the level of expressed emotion (LEE) scale: depressed out-patients and couples from the general community. Br J Psychiatry $170: 520-525$

13. Hooley JM, Teasdale JD (1989) Predictors of relapse in unipolar depressives: expressed emotion, marital distress, and perceived criticism. J Abnorm Psychol 98:229-235

14. Hale WW III, Raaijmakers QAW, Gerlsma J, Meeus WHJ (2007) Does the Level of Expressed Emotion (LEE) questionnaire have the same factor structure for adolescents as it has for adults? Soc Psychiatry Psychiatr Epidemiol 42:215-220

15. Hooley JM, Miklowitz DJ, Beach SRH (2006) Expressed Emotion and DSM-V. In: Beach SRH, Wamboldt MZ, Kaslow NJ, Heyman RE, First MB (eds) Relational processes and DSM-V: neuroscience, prevention and treatment. American Psychiatric Association, Washington, DC, pp 175-191

16. Gerlsma C, van der Lubbe PM, van Nieuwenhuizen C (1992) Factor analysis of the level of expressed emotion scale, a questionnaire intended to measure "perceived expressed emotion". Br J Psychiatry 160:385-389

17. Cole JD, Kazarian SS (1988) The level of expressed emotion scale: a new measure of expressed emotion. J Clin Psychol 44:392-397

18. Startup M (1999) Confirmatory factor analysis of the Level of Expressed Emotion (LEE) scale. Br J Med Psychol 72:421-424

19. Wearden AJ, Tarrier N, Barrowclough C, Zastowny TR, Armstrong-Rahill A (2000) A review of expressed emotion research in health care. Clin Psychol Rev 20:633-666

20. Timbremont B, Braet C (2002) Children's depression inventory: Dutch language manual. Swets \& Zeitlinger, Lisse, The Netherlands

21. Saylor CF, Finch AJ, Spirito A, Bennett B (1984) The children's depression inventory: a systematic evaluation of psychometric properties. J Consult Clin Psychol 52:955-967

22. Björkqvist K, Lagerspetz KMJ, Kaukiainen A (1992) Do girls manipulate and boys fight? Developmental trends in regard to direct and indirect aggression. Aggress Behav 18:117-127

23. Lagerspetz KMJ, Björkqvist K, Peltonen T (1988) Is indirect aggression typical of females? Gender differences in aggressiveness in 11-12 year old children. Aggress Behav 14:403-414
24. Carroll P, Schute R (2005) School peer victimization of young people with craniofacial conditions: a comparative study. Psychol Health Med 10:291-304

25. Owens LD (1996) Sticks and stones and sugar and spice: girls' and boys' aggression in school. Aust J Guid Couns 6:45-55

26. Baerveldt C (1992) Schools and the prevention of petty crime: search for a missing link. J Quant Criminol 8:79-94

27. Baerveldt C, van Rossem R, Vermande M (2003) Pupils' delinquency and their social networks: a test of some network assumptions of the ability and inability models of delinquency. Neth J Soc Sci 39:107-125

28. Arbuckle JL (2006) Amos 7.0 User's Guide. SPSS, Chicago

29. Mroczek DK (2007) The analysis of longitudinal data in personality research. In: Robins RW, Fraley RC, Krueger RF (eds) Handbook of research methods in personality psychology. Guilford Press, New York, pp 543-556

30. Singer JD, Willett JB (2003) Applied longitudinal analysis: modeling change and event occurrence. Oxford, New York

31. Duncan TE, Duncan SC, Strycker LA, Li F, Alpert A (1999) An introduction to latent variable growth curve modeling. Concepts, issues, and applications. Lawrence Erlbaum, Mahwah, NJ

32. Coyne JC, Burchill SAL, Stilles WB (1991) An interactional perspective on depression. In: Snyder CR, Forsyth DO (eds) Handbook of social and clinical psychology. Pergamon, New York, pp 327-349

33. Solomon P, Alexander L, Uhl S (2010) The relationship of case managers' expressed emotion to clients' outcome. Soc Psychiatry Psychiatr Epidemiol 45:165-174

34. Van Humbeeck G, Van Audenhove C, Pieters G, De Hert M, Storms G, Vertommen H, Peuskens J, Heyrman J (2002) Expressed emotion in the client-professional caregiver dyad: are symptoms, coping strategies and personality related? Soc Psychiatry Psychiatr Epidemiol 37:364-371

35. Kuipers E, Watson P, Onwumere J, Bebbington P, Dunn G, Weinman J, Fowler D, Freeman D, Hardy A, Garety P (2007) Discrepant illness perceptions, affect and expressed emotion in people with psychosis and their carers. Soc Psychiatry Psychiatr Epidemiol 42:277-283

36. Hooley JM, Parker HA (2006) Measuring expressed emotion: an evaluation of the shortcuts. J Fam Psychol 20:386-396

37. American Psychiatric Association (2000) Diagnostic and statistical manual of mental disorders, 4th edn., text revision. American Psychiatric Association, Washington, DC

38. Steinberg L, Lamborn SD, Dornbusch SM, Darling N (1992) Impact of parenting practices on adolescent achievement: authoritative parenting, school involvement, and encouragement to succeed. Child Dev 63:1266-1281

39. Gesac V, Schwalbe ML (1986) Parental behavior and adolescent self-esteem. J Marriage Fam 48:37-46 